\title{
The newest ceramic materials for microwaves
}

\author{
V.V. Parshin $^{1}$, E. A. Serov ${ }^{1}$, P.V. Netcvetaeva ${ }^{2}$ \\ ${ }^{1}$ Institute of Applied Physics of RAS, N.Novgorod, Russia, parsh@appl.sci-nnov.ru \\ ${ }^{2}$ OJSC "Magneton Plant", St. Petersburg, Russia
}

The refractive index and absorption $(\tan \delta)$ investigations in different kind of ceramic materials produced in Russia and Germany were made by using the open high-quality Fabry-Perot resonator in the frequency range 50-200 GHz in IAP RAS [1]. The low frequency measurements of the samples were made using cavity resonator by producer of materials [2].

It was established that the quality of these new production is the same as it was in Soviet Union and comparable with the world level. This paper presents the result of investigations.

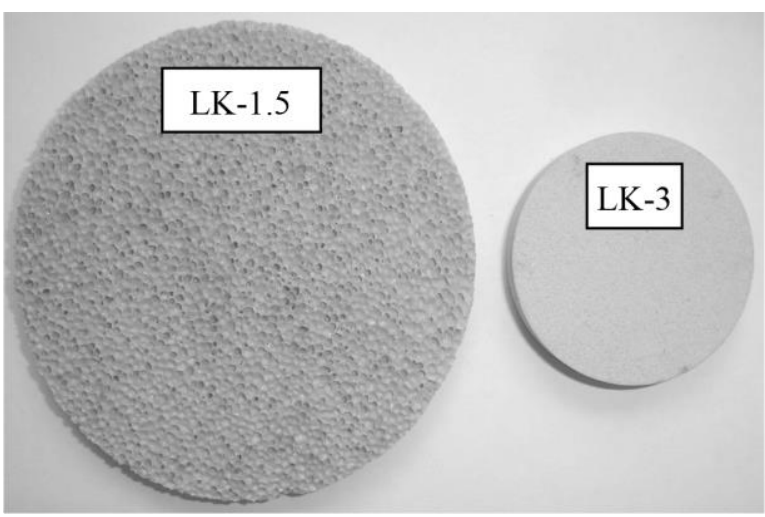

Fig. 1. Vacuum tight foam ceramics produced by JSC "Magneton Plant" with extra low refractive index values

\begin{tabular}{|c|c|c|c|}
\hline & $\begin{array}{c}\mathrm{n} / \mathcal{E} \\
\mathrm{f}=9.4 \mathrm{GHz}\end{array}$ & $\begin{array}{c}\tan \delta\left[10^{-4}\right] \\
\mathrm{f}=9.4 \mathrm{GHz}\end{array}$ & $\rho\left[\mathrm{g} / \mathrm{cm}^{3}\right]$ \\
\hline LK-1.5 & $1.22 / 1.5$ & $\leq 5$ & 0.48 \\
\hline LK-2 & $1.41 / 2$ & $\leq 8$ & 0.8 \\
\hline LK-2.5 & $1.58 / 2.5$ & $\leq 12$ & 1.2 \\
\hline LK-3 & $1.73 / 3$ & $\leq 15$ & 1.5 \\
\hline
\end{tabular}

Low frequency parameters of vacuum tight foam ceramics are presented in Table 1. The loss tangent frequency dependencies of grades LK-2.5 and LK-3 are presented in Fig. 2. The vacuum tight foam ceramics are very interesting materials for microwave applications because it is possible to slightly change the foam content and by this way to get the needed refractive index value. But measurements are meaningless above $200 \mathrm{GHz}$ due to strong losses increasing mainly due to scattering by "foam". By this reason the grades LK-1.5 and LK-2 are not for MM waves.

At the range $100-200 \mathrm{GHz}$ the refractive index increases practically linearly from $n=1.58(9.4 \mathrm{GHz})$ to $n=1.61(170 \mathrm{GHz})$ for $\mathrm{LK}-2.5$ and from $n=1.73$ $(9.4 \mathrm{GHz})$ to $n=1.763(192 \mathrm{GHz})$ for LK-3.

The main parameters of ceramics produced by JSC "Magneton Plant" (St. Petersburg) are presented in Table 2. (at $170 \mathrm{GHz}$ ). The loss tangent frequency dependencies of "traditional" ceramics are practically linear at MM waves and refractive indices are practically constant.

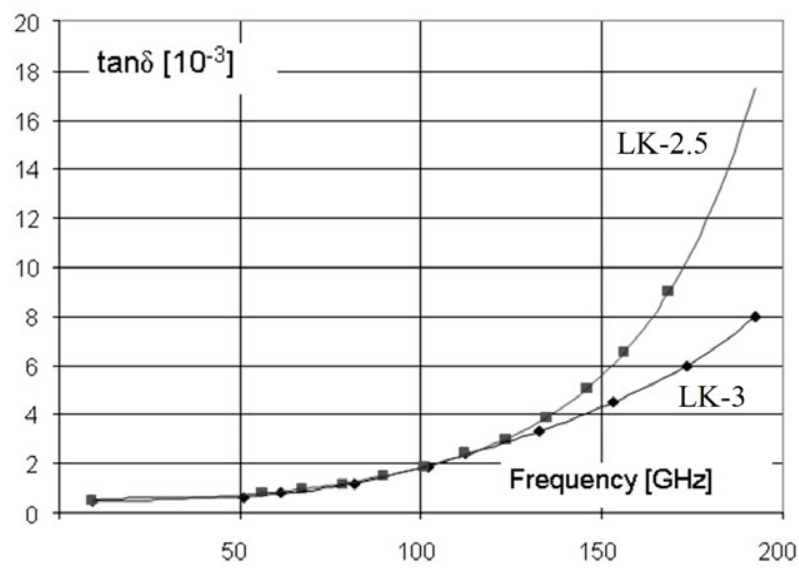

Fig. 2. The loss tangent frequency dependencies of grades LK-2.5 and LK-3

\begin{tabular}{|c|c|c|c|}
\multicolumn{1}{|c}{} & \multicolumn{2}{c|}{ Table } \\
\hline Grade & $\mathrm{n}$ & $\tan \delta\left[10^{-4}\right]$ & $\rho\left[\mathrm{g} / \mathrm{cm}^{3}\right]$ \\
\hline MST-7.3 & 2.685 & 8.5 & 3.18 \\
\hline MST-10 & 3.185 & 9 & 3.37 \\
\hline BK-100M & 3.165 & 4 & 3.98 \\
\hline TK-20 & 4.416 & 50 & 3.78 \\
\hline TK-40 & 6.255 & 37 & 4.78 \\
\hline LK-2.5 & 1.61 & 9 & 1.2 \\
\hline LK-3 & 1.76 & 50 & 1.5 \\
\hline ST-3 & 1.707 & 20 & 1.15 \\
\hline ST-4 & 1.995 & 21 & 1.35 \\
\hline ST-10 & 3.194 & 36 & 2.00 \\
\hline
\end{tabular}

MST grades are the ceramic materials with very stable refractive index values which are traditionally used as constructive elements in microwave technology. Materials can be made in the different form including very complicated ones.

TK grades are thermally stable microwave ceramics which are widely used to create matching and structural elements, substrates for integrated circuits, filters, dielectric resonators with increased requirements for thermostability of dielectric characteristics.

ST grades are microwave dielectrics based on polymers filled with titanium dioxide. In a large-scale production the materials of this series are the basis for the manufacture of products of complex shape with high accuracy by injection molding methods.

BK corundum ceramics are the alumina-based material with various modifying additives. It is traditionally used for manufacturing of substrates for integrated microwave circuits, substrates for high voltage stabilizers, microstrip device supports, as well as high-voltage insulators and energy output windows for medium-power generators.

The main parameters of ceramics produced by "Friatec" (Germany, http://www.friatec.de) are pre- 
sented in Table 3. Fig. 3. presents the results of loss tangent measurements. It is the traditional ceramics on the base of different kind of oxides with different additives for "improving" of electromechanical properties.

\begin{tabular}{|c|c|c|c|c|c|}
\hline $\begin{array}{l}\text { Materials } \\
(170 \mathrm{GHz})\end{array}$ & $\mathrm{n}$ & $\begin{array}{l}\tan \delta \\
{\left[10^{-4}\right]}\end{array}$ & $\begin{array}{l}\mathrm{k} \\
{[\mathrm{W} / \mathrm{cm} \cdot \mathrm{K}]}\end{array}$ & $\begin{array}{l}\alpha \\
{\left[10^{-6}\right.} \\
\left.\mathrm{K}^{-1}\right]\end{array}$ & $\begin{array}{l}\mathrm{E} \\
\mathrm{GPa}\end{array}$ \\
\hline $\begin{array}{l}\text { Degussit } \\
\text { (AlN) }\end{array}$ & 2.91 & 5.8 & $1.8-2$ & 3.6 & 330 \\
\hline $\begin{array}{l}\text { Frialit } \\
\mathrm{HP} 79 \\
\left(\mathrm{Si}_{3} \mathrm{~N}_{4}\right)\end{array}$ & 2.07 & 70 & & & \\
\hline $\begin{array}{l}\text { Degussit } \\
\mathrm{A} 123 \mathrm{HF} \\
\left(\mathrm{Al}_{2} \mathrm{O}_{3}\right)\end{array}$ & 3.14 & 2.7 & 0.35 & 7.3 & 380 \\
\hline $\begin{array}{l}\text { Degussit } \\
\mathrm{Al} 3 \\
\left(\mathrm{Al}_{2} \mathrm{O}_{3}\right)\end{array}$ & 3.313 & 3.6 & 0.35 & 8.2 & 350 \\
\hline $\begin{array}{l}\text { Frialit } 99.7 \\
\mathrm{HF}\left(\mathrm{Al}_{2} \mathrm{O}_{3}\right)\end{array}$ & 3.15 & 2.7 & 0.35 & 7.3 & 350 \\
\hline $\begin{array}{l}\text { Frialit } 99.7 \\
\left(\mathrm{Al}_{2} \mathrm{O}_{3}\right)\end{array}$ & 3.15 & 6 & 0.35 & 7.3 & 350 \\
\hline $\begin{array}{l}\text { Frialit FZT } \\
\left(\mathrm{ZrO}_{2}\right)\end{array}$ & 3.36 & 9 & 0.25 & 7.5 & 460 \\
\hline $\begin{array}{l}\text { Frialit FZM } \\
\left(\mathrm{ZrO}_{2}+\mathrm{Mg}\right)\end{array}$ & 5.46 & 40 & 0.03 & 10.4 & 500 \\
\hline
\end{tabular}

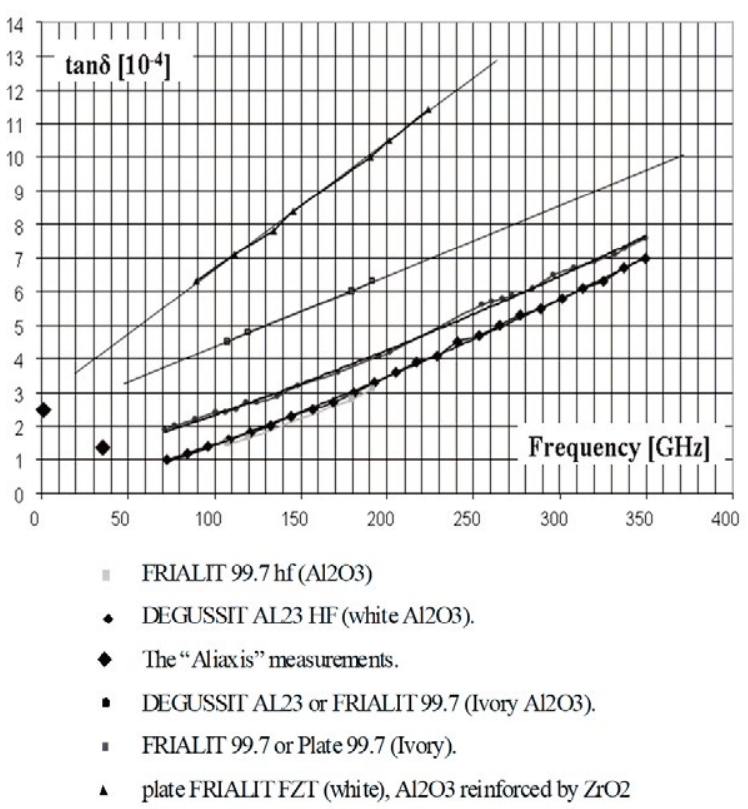

Fig. 3. Loss tangent frequency dependencies of "Friatec" samples

\section{Conclusion}

At present, the JSC "Magneton Plant" (St. Petersburg) (http://www.magneton.ru) has mastered the mass production of 35 grades of dielectric materials continuously overlapping the range of dielectric constant $(\varepsilon)$ values from 1.5 to 120 . Work is in progress to start producing the grades with the values of $\varepsilon \approx$ 140 , as well as to increase the thermal resistance of dielectric materials based on polymers to temperatures of $120 \div 250^{\circ} \mathrm{C}$ [1].

As a result of the research, it can be concluded that a number of materials, with low absorption, are quite suitable for use in $\mathrm{MM}$ and partially in the SubMM ranges for various structures interacting with electromagnetic wave.

The work was partly supported by the Russian Foundation of Basic Research and the Government of the Nizhny Novgorod region, project No. 18-42520015.

\section{References}

1. Parshin, V. V., Tretyakov, M. Yu., Koshelev, M. A., Serov, E.A. Modern resonator spectroscopy at submillimeter wavelengths // IEEE Sensors Journal. 2013. V. 13, No 1. P. 18-23.

2. Firsenkov, A. I., Kanivetc, A. J., Kasatkina, T. C., Ershova, O. M., Ivanova, L. P., Ershova, P. V. Microwave dielectric materials produced by JSC "Magneton Plant" // Proceeding of IV-th All Russian conference Microwave Electronics and microelectronics. St.-Petersburg: ETU «LETI» publishing house , 2015. - V 2. - P. 55-59. 